\title{
Practical and Relevant Self-Report Measures of Patient Health Behaviors for Primary Care Research
}

\author{
Russell E. Glasgow, PbD \\ Marcia G. Ory, $\mathrm{PbD}, M P H^{2}$ \\ Lisa M. Klesges, $\mathrm{PbD}^{3}$ \\ Maribel Cifuentes, $\mathrm{RN}^{4}$ \\ Douglas H. Fernald, $M A^{4}$ \\ Larry A. Green, $M D^{4}$ \\ ${ }^{1}$ Kaiser Permanente, Denver, Colo \\ ${ }^{2}$ Texas A\&M University System, College \\ Station, Tex \\ ${ }^{3}$ Mayo Clinic, College of Medicine, \\ Rochester, Minn \\ ${ }^{4}$ Prescription for Health, University \\ of Colorado Health Sciences Center, \\ School of Medicine, Denver, Colo
}

Conflicts of interest: none reported

\section{CORRESPONDING AUTHOR}

Russell E. Glasgow, PhD

Clinical Research Unit

Kaiser Permanente Colorado

335 Road Runner Lane

Penrose, CO 81240

russg@ris.net

\begin{abstract}
PURPOSE With increasing evidence for the value of behavior change counseling, there is a need for health behavior measurements that can be implemented in primary care research. This article discusses criteria for and reviews self-report measures to briefly assess cigarette smoking, eating patterns, physical activity, and risky drinking across the life course. It then proposes pragmatic measures for use in practice-based research.
\end{abstract}

METHODS Drawing from literature reviews, previous multisite studies, personal communications with experts in the field, and guidance from an expert panel, we identified self-report behavior change measures and gave priority to items that addressed Healthy People 2010 goals, as well as those that were practical (ie, shorter, and easier to score and use for intervention), were sensitive to change, and produced results that could directly inform primary care intervention.

RESULTS Separate recommendations are described for measures for adults and for children/adolescents. We recommend a set of 22 items for adults and 16 items for adolescents to track succinctly their status on the 4 health behaviors above. Perfected measures remain elusive: newly developed measures of physical activity and eating patterns are recommended, and in general, the brief measures for adults are currently better validated than are the child measures.

CONCLUSIONS A set of totally satisfactory practical instruments for measuring behavior change in primary care settings does not yet exist. There is sufficient progress to encourage use of and further research on the proposed items. Use of a common set of items across different interventions and projects will help to advance clinical and behavioral research in primary care settings.

Ann Fam Med 2005;3:73-81. DOI: 10.1370/afm.261.

\section{INTRODUCTION}

I ealth behavior counseling in primary care settings holds great potential for disease prevention and management. ${ }^{1-3}$ Emerging evidence points to the importance of the physician as a change agent ${ }^{4}$ the efficacy of health behavior change interventions in primary care settings, ${ }^{5}$ and the value of behavioral change interventions for high-risk populations. ${ }^{6}$

It is timely to emphasize health behavior counseling in primary care given the large potential impact of personal behavior change on premature death and avoidable suffering. ${ }^{1,7,8}$ The underperformance of the US health care system is acknowledged and accompanied by keen interest to improve. ${ }^{9}$ The 3 primary care medical specialties, as well as primary care nurse practitioners and physician's assistants, exist in sufficient numbers to make feasible greater attention to the health needs of primary care patients. ${ }^{10-12}$ Also, all 3 of the primary care physician specialties-pediatrics, family medicine, and general internal medicine_-are now calling for revisions in training 
and practice congruent with a greater emphasis on the health behaviors of their patients. ${ }^{13,14}$

Evaluation of behavioral interventions in primary care research requires appropriate assessments of targeted health behaviors. Valid assessment methods are needed to identify patients who could benefit from interventions, to inform the design of intervention strategies, and to evaluate intervention success. Whereas many instruments are available to assess health behaviors, ${ }^{15}$ few have been designed for or used in primary care settings.

Challenges for primary care settings include the "tyranny of competing demands."16 Lengthy measures are not realistic to administer in practice-based research. ${ }^{17}$ Practical measures are needed that are broadly applicable, able to be self-administered, and appropriate for a range of age and cultural groups, and that have sufficient validity and reliability. Also, measures should be congruent with national public health goals and sensitive to intervention effects, because the goal is to produce improvements in individual health as well as affect population health.

Measures for primary care research need to be brief because of the lack of time or supervision to complete lengthy instruments. Additionally, because primary care is comprehensive ${ }^{18,19}$ — concerned with improving a variety of risk factors and conditions-focusing on 1 or 2 areas should not result in worse care in other areas. Unfortunately, almost all "gold standard" assessment procedures have focused on 1 health behavior in isolation and attain part of their precision by being relatively lengthy, burdensome, or expensive.

In this article, we focus on assessment of 4 health behaviors that collectively account for the majority of illness and mortality in the United States: cigarette smoking, eating patterns, physical inactivity, and risky drinking. ${ }^{8,20}$ This work was conducted as part of Prescription for Health $(\mathrm{P} 4 \mathrm{H}){ }_{1}{ }^{21}$ a program of the Robert Wood Johnson Foundation and the Agency for Healthcare Research and Quality. In its first round, $\mathrm{P} 4 \mathrm{H}$ funded 17 practice-based research networks to field test evidence-based strategies to improve the delivery, feasibility, and reach of behavior change counseling for these 4 health behaviors in primary care practices. A major goal of the second round is to assess the extent to which interventions are effective in attaining patient behavior change. A common set of brief measures is necessary to compare outcomes across settings, interventions, and populations.

Our purposes in this article are to (1) discuss issues in selecting measures of physical activity, risky drinking, cigarette smoking, and eating patterns that are appropriate for adult or pediatric primary care research, (2) identify specific, practical behavioral assessments that could be implemented in primary care research without adding undue burden to patients or clinicians; and (3) discuss implementation, conditions of administration, and directions for future research.

\section{METHODS Context}

To understand the current state of measurement in primary care studies, we reviewed assessments proposed by grantees in the first round of $\mathrm{P} 4 \mathrm{H}$ funding. Among the 17 sites, 15 focused on physical activity, 7 on risky drinking, 11 on cigarette smoking, and 14 on eating patterns. All projects addressed at least 2 health behaviors. Despite the common health behaviors addressed, there were few commonalities in the instruments selected to measure health behaviors. The initial $\mathrm{P} 4 \mathrm{H}$ projects proposed the following behavioral measures.

\section{Physical Activity}

Physical activity logs, recalls, weekly assessments, and screening questions were all used. Referenced questionnaires or sources included Physical Activity Scale for the Elderly (PASE), ${ }^{22,23}$ PACE project assessment, ${ }^{24}$ Summary of Diabetes Self-Care Activities, ${ }^{25}$ Healthy People 2010, ${ }^{3}$ National Health Interview Survey (NHIS), ${ }^{26}$ Behavioral Risk Factor Surveillance System-BRFSS, ${ }^{27}$ and Guidelines for Adolescent Prevention Services (GAPS). ${ }^{28}$

\section{Risky Drinking}

Number of alcoholic drinks per week, quantity of drinks, social aspects of drinking, and alcohol exposure and risk (adolescents only) assessments were all used. Referenced questionnaires or sources included the Five Shot questionnaire, ${ }^{29}$ Alcohol Use Disorders Identification Test (AUDIT), ${ }^{30,31}$ NHIS, ${ }^{26}$ BRFSS,$^{27}$ and GAPS. ${ }^{28}$

\section{Cigarette Smoking}

Questions included whether the patient ever smoked, was a current smoker, number cigarettes smoked and quit attempts. Referenced questionnaires or sources included Summary of Diabetes Self-Care Activities, ${ }^{25}$ NHIS, ${ }^{26}$ BRFSS $^{27}$ and GAPS. ${ }^{28}$

\section{Eating Patterns}

Food diaries, logs, 24-hour dietary recall, and nutrition intake questionnaires were used. Referenced sources included the Summary of Diabetes Self-Care Activities, ${ }^{25}$ Block Brief 2000 Questionnaire, ${ }^{32}$ "Rate Your Plate,"33 NHIS, ${ }^{26}$ BRFSS, ${ }^{27}$ Healthy People 2010, ${ }^{3}$ and GAPS. ${ }^{28}$

The length of the proposed assessment instruments was surprising. Subsequent conversations with $\mathrm{P} 4 \mathrm{H}$ grantees suggested that it was difficult to implement these measurement tools in practice. Although many 


\begin{tabular}{|c|c|}
\hline Criteria & Rationale/Description \\
\hline \multicolumn{2}{|l|}{ Primary } \\
\hline 1. Practicality & $\begin{array}{l}\text { A composite criterion including length; ease of administration, scor- } \\
\text { ing, and interpretation; appropriateness to a wide range of set- } \\
\text { tings and populations; and in the public domain, to reduce costs }\end{array}$ \\
\hline $\begin{array}{l}\text { 2. Relationship to clinical } \\
\text { and public health goals }\end{array}$ & $\begin{array}{l}\text { Assessment of success toward achieving quantifiable public health } \\
\text { goals linked to health behavior change objectives. For example, } \\
\text { preference was given to results that could be linked to achieve- } \\
\text { ment of Healthy People } 2010 \text { goals }\end{array}$ \\
\hline 3. Validity & $\begin{array}{l}\text { Agreement with reference standard measures. We gave moderate } \\
\text { emphasis to convergent and divergent validity (correlations with } \\
\text { other established measures of the same behavior and lack of cor- } \\
\text { relation with other constructs) }\end{array}$ \\
\hline 4. Sensitivity to change & $\begin{array}{l}\text { Ability of a measure to detect improvements resulting from effective } \\
\text { interventions was given the largest weight. To achieve sensitivity } \\
\text { to change, an instrument must demonstrate other characteristics, } \\
\text { such as test-retest reliability. The primary purpose of including } \\
\text { behavioral measures was to evaluate whether significant improve- } \\
\text { ments are produced }\end{array}$ \\
\hline $\begin{array}{l}\text { 5. Relation to behavioral } \\
\text { interventions }\end{array}$ & $\begin{array}{l}\text { Degree to which instruments were behaviorally based and thus } \\
\text { directly related to } \mathrm{P} 4 \mathrm{H} \text { interventions } \mathrm{s}^{21} \text { (eg, it is less valuable to } \\
\text { have a recall that produces detailed dietary nutrients, than mea- } \\
\text { sures that assess changes in eating behavior) }\end{array}$ \\
\hline \multicolumn{2}{|l|}{ Secondary } \\
\hline $\begin{array}{l}\text { 6. Cultural and literacy } \\
\text { issues }\end{array}$ & $\begin{array}{l}\text { Extent to which measures were appropriate for and had been trans- } \\
\text { lated into and validated in other languages, especially Spanish }\end{array}$ \\
\hline $\begin{array}{l}\text { 7. Norms and breadth } \\
\text { of use }\end{array}$ & $\begin{array}{l}\text { Having data on national or regional norms. Data from instruments } \\
\text { with well-established norms allow comparison of interventions } \\
\text { and populations to larger reference groups }\end{array}$ \\
\hline 8. Age appropriateness & $\begin{array}{l}\text { Appropriate across the full age range and functional levels. Given } \\
\text { special attention for children and adolescents }\end{array}$ \\
\hline 9. Reliability & $\begin{array}{l}\text { Given the brevity required, we did not place strong emphasis on } \\
\text { internal consistency ( } \alpha \text { coefficients), but gave considerable weight } \\
\text { to test-retest reliability }\end{array}$ \\
\hline $\begin{array}{l}\text { 10. Usability for feedback } \\
\text { and interventions }\end{array}$ & $\begin{array}{l}\text { Scales that can be scored immediately or can identify areas for } \\
\text { improvement to help with patient goal setting }\end{array}$ \\
\hline
\end{tabular}

(NIH) Web sites, using the search terms "nutrition," "diet," "eating," "smoking," "cigarette smoking," "alcohol consumption," "risky drinking," "exercise," and "physical activity" with "selfreport," "measurement," "primary care," and "assessment." In particular, reviews from 2 major NIHfunded health behavior change consortia, the Behavior Change Consortium $^{34}$ and the Health Maintenance Consortium (http:// hmcrc.srph.tamu.edu/default. aspx), provided excellent information on potential instruments.

An initial subset of measures was identified by the first 3 authors, with exclusion of measures that were longer than 10 items or that were not appropriate for self-administration. Candidate measures were initially reviewed to establish their suitability, and tables were developed that outlined information on the various selection criteria.

Summary information and tables were presented to a consensus panel of $\mathrm{P} 4 \mathrm{H}$ program representatives and invited of the proposed instruments had demonstrated validity for screening, their ability to detect changes in health behaviors is uncertain.

\section{Procedures and Criteria Used in Making Recommendations}

To identify practical measures for assessing and tracking health behaviors, we needed to specify selection criteria. Greatest weight was given to 5 primary criteria: practicality, clinical and public health relevance, validity, sensitivity to change, and relation to behavioral intervention. The 5 secondary criteria listed at the bottom of Table 1 were also considered. Because child and adolescent risk behaviors differ in frequency and nature from those of adults, separate assessments were generally necessary.

Candidate measures were identified from several sources, including instruments implemented in the first phase of $\mathrm{P} 4 \mathrm{H}$, review of published literature, suggestions of professional contacts (because many instruments are under development) and consensus statements and guidelines for recommended assessments. Searches were conducted on PubMed and National Institute of Health experts. The panel included 12 experts in the areas of primary care, practice-based research, and quantitative and qualitative analyses. The panel agreed that priority for further recommendations should be based on assessments demonstrated to have (1) sensitivity to change or intervention effects ${ }_{i}(2)$ broad applicability, especially to minority populations or validated in Spanish; (3) normative data; and (4) usefulness for intervention planning. Final revised recommendations were based on discussion by this consensus panel.

The following key issues emerged from the panel discussion: (1) the number of items needed to be even briefer than originally proposed if the expectation was that all practices would assess multiple behaviors; (2) the wording of several items did not apply to primary care $_{i}(3)$ response formats of several items needed to be changed to fit time frames relevant to practice-based research; (4) a recommended list of brief items should be provided, as well as a secondary recommendation where warranted, of slightly longer instruments if they had superior qualities; and (5) sensitivity to change was very important, and several widely used screening measures did not meet this criterion. 
Figure 1. Adult Measures of Behavior Change

\section{Physical activity (RAPA) $)^{35 *}$}

Scoring - see Web site: http://hmcrc.srph.tamu.edu/Measurement\%20folder/PA/RAPA\%20fnl\%201004.doc

Physical activities are activities where you move and increase your heart rate above its resting rate, whether you do them for pleasure, work, or transportation.

The following questions ask about the amount and intensity of physical activity you usually do. The intensity of the activity is related to the amount of energy you use doing these activities.

Examples of physical activity intensity levels:

\section{Light activities}

Your heart beats slightly faster than normal

You can talk and sing

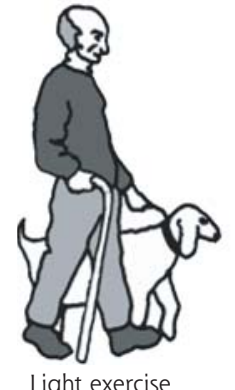

Light exercise

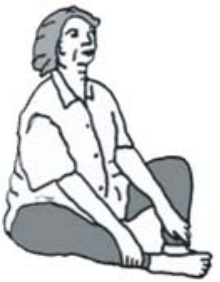

Light stretching

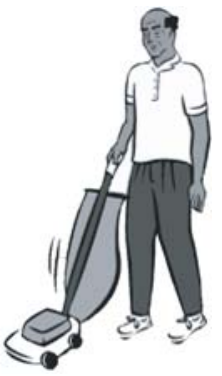

Light vacuuming or yard work

Moderate activities

Your heart beats faster than normal

You can talk but not sing

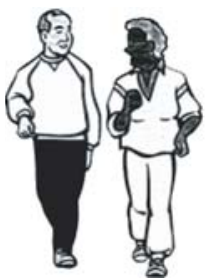

Brisk walking

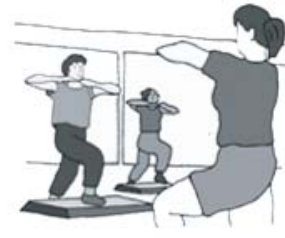

Aerobics class

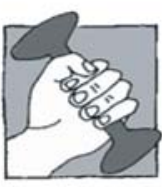

Strength training Swim gently
Vigorous activities

Your heart rate increases a lot

You can't talk, or your talking is broken up by large breaths

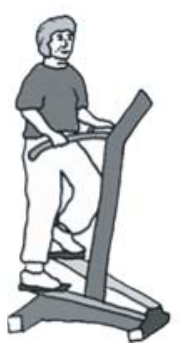

Aerobics classes

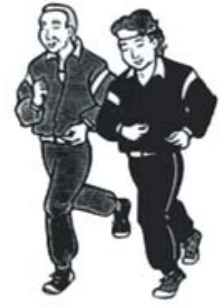

Jogging, Running, or Power Walking

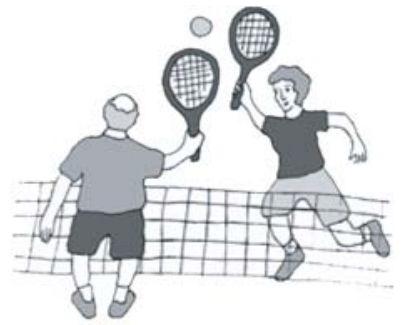

Singles tennis, Racquetball, Pickle ball

How physically active are you? (answer Yes or No to each)

I rarely or never do any physical activities.

I do some light and/or moderate physical activities, but not every week.

I do some light physical activity every week.

I do moderate physical activity every week but less than 5 days per week or less than 30 minutes on those days.

I do vigorous physical activities every week, but less than 3 days per week or less than 20 minutes on those days.

I do 30 minutes or more per day of moderate physical activities 5 or more days per week.

I do 20 minutes or more per day of vigorous physical activities 3 or more days per week.

I do activities to increase muscle strength, such as lifting weights or calisthenics, once a week or more.

I do activities to improve flexibility, such as stretching or yoga, once a week or more.

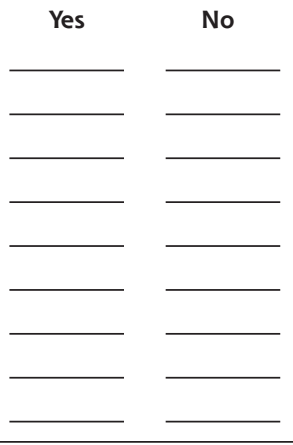

*Adapted with permission from "How Physically Active Are You?" from the University of Washington Health Promotion Research Center, Seattle, Wash. 


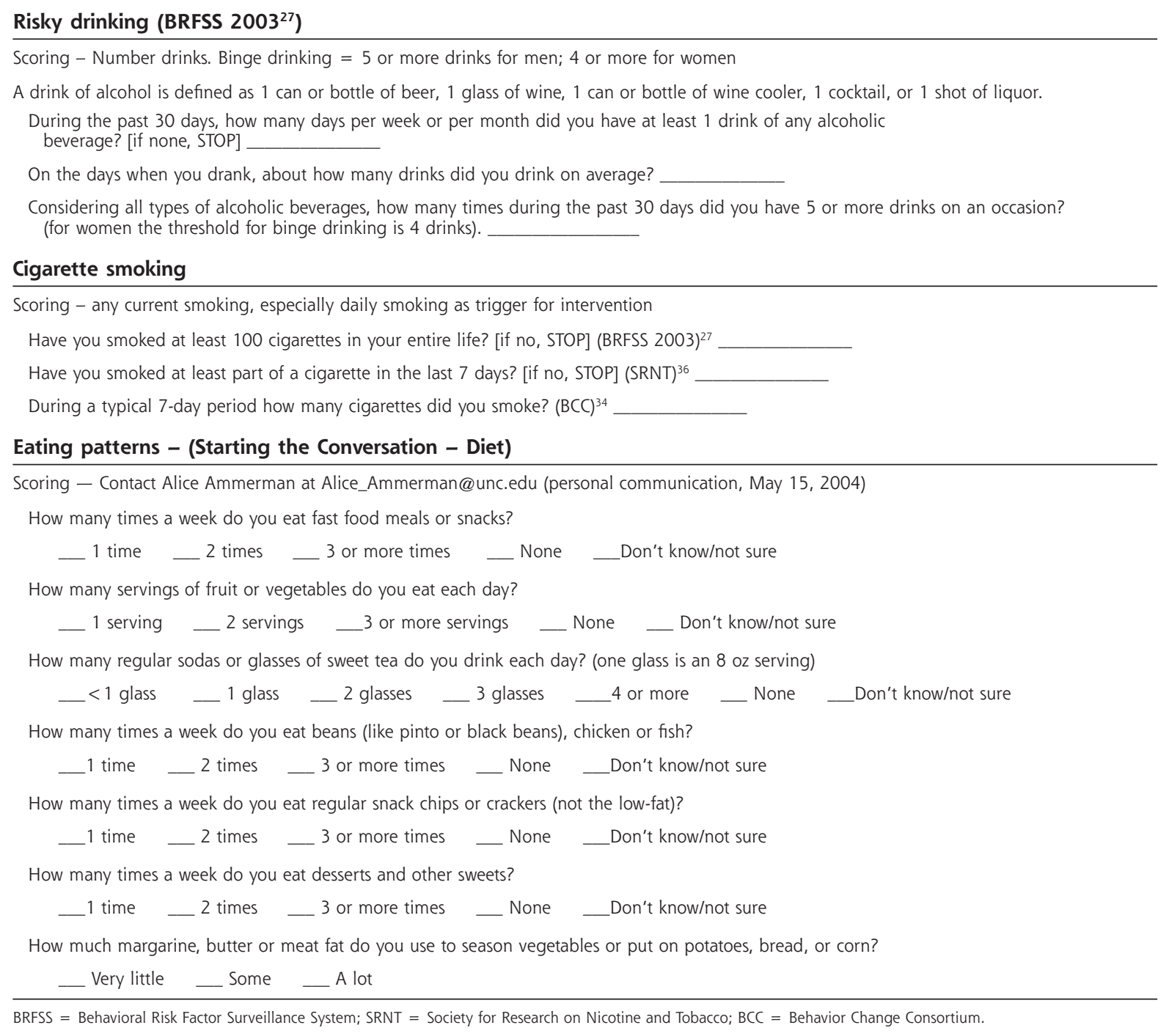

\section{RESULTS}

For each target behavior, we offer both a primary recommendation, and in most cases, a secondary recommendation, which often involves an elaboration of the primary measure that might be applicable for sites wishing to devote more time or priority to that behavior. Our primary recommendations are summarized in Figure $1^{34-36}$ and Table $2^{27,37-41}$ (which are available online at http://www.annfammed.org/cgi/con$8 m_{\mathrm{I}}$ tent/full/3/1/73/DC1); secondary recommendations are in Appendixes $1^{38,39,42-44,45}$ and 22,27,30,31,36 (which are available online at http://www.annfammed. org/cgi/content/full/3/1/73/DC1). For adults, 22 items are recommended as a minimum assessment across all 4 behaviors. The corresponding number for adolescents, ages 12 to 17 years is 16 , and 12 items for younger children. Although many of the items recommended are from validated instruments, seldom was it possible to include entire instruments. Several of our recommendations endorsed new instruments, and potential users should review these measures for updates before implementing. Table $3^{25,27,34,36-45}$ (available online only at http://www.annfammed.org/ cgi/content/full/3/1/73/DC1) summarizes the characteristics of recommended measures.

\section{Recommended Measures for Adolescents and Children}

Only a few measures of health behaviors in children or adolescents were located that fit most of the desired criteria, and none were identified that reported sensitivity to change. Some instruments with acceptable validity and reliability were identified, but they were too long or cumbersome to be feasible in primary care settings. Given the paucity of available measures, recommended items were sometimes based on items 
from adult samples or that had face validity but no established measurement properties in adolescents and children.

The following measures are recommended for assessing adolescent and child behavior. Table 3 presents the actual items.

\section{Physical Activity}

Adolescents. Three items are recommended, including 2 items from the PACE + project $^{37}$ and 1 item from the Youth Risk Behavior Surveillance System (YRBSS). ${ }^{38}$ The PACE + items, which assess frequency of physical activity in the last 7 days and in a typical week, have been validated in a diverse population of middleschool adolescents. The items demonstrated acceptable measurement properties (sensitivity $71 \%$, specificity $63 \%$; significantly correlated with accelerometer readings $r=.40, P<.001) .{ }^{37}$ In addition, our panel believed it was important to assess sedentary behavior, so an item from the YRBSS was recommended to evaluate hours of television watched on an average school day. All recommended items can be used to address the Healthy People 2010 goals. A secondary recommendation was to assess sedentary behaviors of computer and video game use via an adaptation of the YRBSS item that assesses television viewing. Measurement characteristics and normative data are not currently available for this item.

Younger Children. Obtaining reliable and valid self-reported physical activity in younger children is problematic. ${ }^{46,47}$ No feasible and reliable self-report instruments were identified for children, and objective measures such as activity monitors were not considered practical. Therefore, no recommendation is made for this age-group.

\section{Risky Drinking}

Adolescents. The 3 items recommended are based on questions from the 2003 BRFSS. While our panel recognized that overall prevalence of alcohol use would be lower in adolescents compared to adults, these items were recommended to identify current problems with alcohol consumption. They are also useful for calculating Healthy People 2010 goal attainment.

As a secondary assessment of risky drinking, 6 items from the CRAFFT screening test are recommended. ${ }^{42}$ This measure has been validated in clinical settings with diverse populations of adolescents aged 13 to 19 years and has demonstrated reliability and validity. ${ }^{42-44}$ An adapted version of the instrument that screens only for alcohol, instead of alcohol and drug use, was believed to be most practical. Normative data are available on the longer CRAFFT instrument, but cutoffs for specific alcohol-related problems are not.
Children. Risky drinking in children younger than 12 years is infrequent, ${ }^{48}$ and validated measures of susceptibility are not currently available.

\section{Smoking}

Adolescents. Two items from the Smoking Uptake Continuum $^{39}$ assessment are recommended. These items assess susceptibility to smoking, with the first item asking about experimentation with cigarettes and the second asking how many days, in the last 30, that an adolescent smoked. The second item can be used to calculate attainment of Healthy People 2010 goals.

The secondary recommendation for adolescent smoking is to include 8 additional items from the Smoking Uptake Continuum (Appendix 1). This 10item measure ${ }^{39}$ categorizes youth into 7 levels of smoking behavior from committed never smoker to current established smoker. The instrument is validated with adolescents aged 12 to 18 years and has demonstrated good predictive validity ( $<6 \%$ committed never smokers progress to established smokers over a 3- to 4-year period, susceptible never smokers are 2 to 3 times more likely to initiate smoking over a 3- to 4-year period than are committed never smokers).

Children. A primary recommendation is to assess children's susceptibility to future smoking based on 4 items from Jackson's Susceptibility to Smoking scale. ${ }^{41}$ This measure has been validated in children in grades 3 to 5 and found to be predictive of smoking initiation 2 years after assessment.

\section{Eating Patterns}

Adolescents. The literature review identified a few measures that assessed nutrient intake and had been validated in clinical settings with adolescents and children. ${ }^{49,50}$ These instruments were considered too long, however, to be feasible in primary care settings. The panel also emphasized the importance of assessing dietary behaviors and food groups, such as fruits and vegetables, rather than nutrients, for use in behavioral counseling.

We recommend an 8 -item instrument ${ }^{40}$ developed by Ammerman and colleagues (Alice Ammerman, personal communication, May 15, 2004) that assesses dietary patterns, such as frequency of fast-food intake, fat snack intake, and sweetened beverage consumption. The instrument was designed to be completed by adolescents on their own and together with parents for younger children. It was designed using literature review, expert input, and feasibility testing, and measurement properties are currently being evaluated.

A secondary recommendation is a 2-item assessment of fruit and vegetable intake developed by the PACE+ project. ${ }^{45}$ These items are consistent with Healthy 
People 2010 goals and have been validated in a diverse population of middle school-aged adolescents. They have demonstrated acceptable measurement properties (significant correlations with 3-day food record; sensitivity $81 \%$, specificity $47 \%$, positive predictive value $79 \%)$. Although the items have not been validated in younger children, the panel believed that younger children could complete these items with assistance from a parent or guardian.

\section{Recommended Measures in Adults}

Our review indicated that there are now several practical lifestyle measures being tested for use in adults, 2 of which are primary recommendations. We attempted to select instruments that could bridge the vast diversity of adult populations (Figure 1). ${ }^{35}$

\section{Physical Activity}

Primary measure. The Rapid Assessment Physical Activity Scale (RAPA). ${ }^{35}$ This scale involves 9 yes/no items assessing the type and amount of physical activity in which adults engage. Clinicians and measurement experts at the University of Washington developed this scale for primary care settings. In preliminary validation studies it compares well with longer scales. A major advantage is that it enables respondents to visualize differences in activity intensity. Pictures and examples can be made culturally and setting relevant. Other advantages are a quick and easy scoring sheet, and availability in different languages (eg, Spanish and Vietnamese).

Secondary measure. Seven items from the BRFSS. ${ }^{27}$ The main advantage of the BRFSS is that it permits comparison with national norms, and Spanish translations are available. Although separating types of activity may be helpful, the original purpose of the BRFSS was for surveillance, not intervention tracking. Additionally, responses are often ambiguous because of respondent failure to differentiate among intensity levels. We recommend RAPA over this scale, for likelihood of more accurate reporting, and the use of graphics to clarify different levels of activity. Both scales can be mapped to Healthy People 2010 recommendations.

\section{Risky Drinking}

Primary measure. Three items from the BRFSS. ${ }^{27}$ These items offer a fast, simple way to detect risky drinking and to examine changes in binge drinking. Findings can be compared with national norms and related to Healthy People 2010 goals.

Secondary measure. AUDIT. ${ }^{30,31}$ This 10-item instrument is often used in national and international studies to screen for risky drinking, and it is available in Spanish. It is less relevant for intervention studies and assessing change over time than it is for screening.
Time frames of many of the AUDIT items prevent precise change estimates.

\section{Cigarette Smoking}

Primary measure. Three items from national health surveys. ${ }^{27,34,36}$ These items (Figure 1) are recommended to assess whether respondents ever smoked, their current smoking status, and extent of smoking. Individual items are taken from national surveys, and thus there are normative data; however, with the exception of the second item, these are not standard measures from major trials to evaluate smoking interventions. There was concern about wording of some of the lengthier and more complex items used in smoking cessation trials. The recommended items form an efficient condensed set (if persons answer "no" to initial items, they skip the remaining questions) and allow tracking on Healthy People 2010 goals.

Secondary measure. Six items recommended by the Society for Research on Nicotine and Tobacco ${ }^{36}$ (embedded within 3 questions in Appendix 2) to measure cessation in cessation trials. These items reflect expert consensus assessment of abstinence parameters (eg, temporal intervals, slips). They are recommended for those emphasizing smoking behaviors. This approach recognizes that there will be relapses and also allows survival analyses.

\section{Eating Patterns}

Primary measure. Starting the Conversation (STC) - Diet. (Alice Ammerman, personal communication, May 15, 2004) This 7 -item scale comes out of a program of nutrition research by Ammerman and colleagues. The advantage of this scale is its simplicity and relative brevity. It also assesses food patterns vs nutrient or fat intake and provides tailored strategies for behavioral counseling. The validity of the STC is currently being examined in the WISEWOMAN Study, ${ }^{51}$ with comparisons to longer, more traditional nutritional assessments.

Secondary measure. The Summary of Diabetes Self-Care Activities (SDSCA) ${ }^{25}$ This scale includes 4 dietary items that address the most commonly targeted dietary recommendations - eg, low fat, high fiber, and increased fruit and vegetable intake. The questions correlate reasonably well with much longer reference standard instruments. The SDSCA has been widely used in various formats (paper and computer administered) and found to be sensitive to change in intervention studies with diabetes patients, but has not been validated in nondiabetic study samples. The questions seem applicable to nondiabetic adults, but we recommend the STC items because they lead directly to intervention planning. 


\section{DISCUSSION}

Our goal was to derive a set of practical, yet valid, items that could evaluate patient behavior change in the 4 priority areas across the diverse $\mathrm{P} 4 \mathrm{H}$ projects. This same set of items should be appropriate for most primary care-based research and practices in the United States. Given our mandate, the failure of traditional review procedures to identify many appropriate measures, and the frequent lack of information on key criteria (eg, sensitivity to intervention; cultural appropriateness), we were forced to rely to a moderate extent upon informal networks of leading researchers and organizations, and upon subjective estimates of which items best fulfilled our criteria.

Consistent use of the proposed measures would greatly improve the science of health promotion among primary care patients. It is difficult to compare results of studies from different interventions and populations if each study uses measures of differing or unknown reliability, validity, and sensitivity to change-even if results are converted to standard units such as effect size. We propose the items in Figure 1 and Table 2, as a relatively succinct set of items for use in primary care research and practical clinical trials. ${ }^{52,53}$ These recommendations should also be useful to clinicians and health plans for identification of health behavior change needs and quality improvement efforts.

Additional research is needed on these measures. Some items are very new, and more data are needed on their continued performance. Several items recommended have not been fully tested in terms of traditional psychometric standards. There is, however, a compelling need for a practical set of items appropriate for assessing multiple health behaviors in primary care. We posit that the recommended items are a better solution to this need than recommending nothing, or a much longer, and less clinically useful set of measures that would be much less likely to be used. These recommendations should be periodically reevaluated and revised as new information becomes available. This report is limited to assessments of these 4 health behaviors and does not address other important selfmanagement goals that may be set between patients and their health care team. ${ }^{54}$ We restricted our focus to self-report measures and did not review direct observation or mechanical instrumentation methods. ${ }^{55}$

We recommend 3 specific areas of future research. First, these proposed items should be compared directly to "gold standard" assessments. Second, more studies are needed of their sensitivity to change; acceptability in a spectrum of family medicine, internal medicine, and pediatric practices; and results under different conditions of administration, in particular computerautomated assessment. Finally, research using modern approaches, such as item response theory, is needed to determine whether it is possible to further streamline these assessments.

To read or post commentaries in response to this article, see it online at http://www.annfammed.org/cgi/content/full/3/1/73.

Key words: Health behavior; risk factors; needs assessment; review; primary health care

Submitted September 15, 2004; submitted, revised November 29, 2004; accepted December 1, 2004.

Funding support: This project was supported by the Robert Wood Johnson Foundation in supporting the Prescription for Health project.

\section{References}

1. U. S. Preventive Services Task Force. Guide to Clinical Preventive Services. 2nd ed. Baltimore, MD: Williams \& Wilkins; 1996.

2. Centers for Disease Control and Prevention. The Guide to Community Preventive Services. 2002 Available at: http://www.thecommunityguide.org.

3. U. S. Department of Health and Human Services. Healthy People 2010: Understanding and Improving Health. Washington, DC: Government Printing Office; 2000.

4. Ockene IS, Hebert JR, Ockene JK, et al. Effect of physician-delivered nutrition counseling training and an office-support program on saturated fat intake, weight, and serum lipid measurements in a hyperlipidemic population: Worcester Area Trial for Counseling Hyperlipidemia (WATCH). Arch Intern Med. 1999;159:725-731.

5. Whitlock EP, Orleans CT, Pender N, Allan J. Evaluating primary care behavioral counseling interventions: an evidence-based approach. Am J Prev Med. 2002;22:267-284.

6. Knowler WC, Barrett-Connor E, Fowler SE, et al. Reduction in the incidence of type 2 diabetes with lifestyle intervention or metformin. N Engl J Med. 2002;346:393-403.

7. McGinnis JM, Foege WH. Actual causes of death in the United States. JAMA. 1993;270:2207-2212.

8. Mokdad AH, Marks JS, Stroup DF, Gerberding JL. Actual causes of death in the United States. JAMA. 2004;291:1238-1245.

9. Institute of Medicine, Committee on Quality of Health Care in America. Crossing the Quality Chasm: A New Health System for the 21st Century. Washington, DC: National Academy Press; 2001.

10. Luire JD, Goodman DC, Wennberg JE. Benchmarking the future generalist workforce. Eff Clin Pract. 2002;5:58-66.

11. Shipman LA, Lurie JD, Goodman DC. The general pediatrician: projection of future workforce supply and requirements. Pediatrics. 2004;113:435-442.

12. Council on Graduate Medicine Education. Physician Workforce Policy Guidelines for the U.S. 2000-2020. Albany, New York: Center for Health Workforce Studies, University of Albany; 2004.

13. Larson EB, Fihn SD, Kirk LM, et al. The future of general internal medicine. Report and recommendations from the Society of General Internal Medicine (SGIM) Task Force on the Domain of General Internal Medicine. J Gen Intern Med. 2004;19:69-77.

14. Future of Family Medicine Project Leadership Committee. The future of family medicine: a collaborative project of the family medicine community. Ann Fam Med. 2004;2:S3-S32.

15. Shumaker SA, Schron EB, Ockene JK, McBee WL. The Handbook of Health Behavior Change. 2nd ed. New York, NY: Springer Publishing Company; 1998. 
16. Stange KC, Woolf SH, Gjeltema K. One minute for prevention: the power of leveraging to fulfill the promise of health behavior counseling. Am J Prev Med. 2002;22:320-323.

17. Cherry DK, Burt CW, Woodwell DA. National Ambulatory Medical Care Survey: 2001 summary. Adv Data. 2003;22:1-44.

18. Starfield B. Primary care: Balancing Health Needs, Services, and Technology. Cambridge: Oxford University Press; 1998.

19. Institute of Medicine. Primary Care: America's Health in a New Era. Washington, D.C.: National Academy of Sciences; 1996.

20. Fine LJ, Philogene GS, Grambling R, Coups EJ, Sinha S. Prevalence of multiple behavioral risk factors in the United States: Results from the 2001 National Health Interview Survey. Am J Prev Med. 2004;27(2S): 18-24.

21. Robert Wood Johnson Foundation, Agency for Healthcare Research and Quality. PrescriptionForHealth Web site. Available at: http://www. prescriptionforhealth.org.

22. Washburn RA, Smith KW, Jette AM, Janney CA. The physical activity scale for the elderly (PASE): development and evaluation. J Clin Epidemiol. 1993;46:153-162.

23. Washburn RA, McAuley E, Katula J, Mihalko SL, Boileau RA. The physical activity scale for the elderly (PASE): evidence for validity. $J$ Clin Epidemiol. 1999;52:643-651.

24. Calfas KJ, Sallis JF, Zabinski MF, et al. Preliminary evaluation of multi-component program for nutrition and physical activity change in primary care: PACE + for adults. Prev Med. 2002;34:153-161.

25. Toobert DJ, Hampson SE, Glasgow RE. The summary of Diabetes Self-Care Activities Measure: results from seven studies and revised scale. Diabetes Care. 2000;23:943-950.

26. U. S. Department of Health and Human Services. National Health Interview Survey (NHIS). 2004. Available at: http://www.cdc.gov/ nchs/nhis.htm.

27. U. S. Department of Health and Human Services. Behavioral Risk Factor Surveillance System. 2004. Available at: http://www.cdc.gov/ brfss/index.htm.

28. Elster A. The American Medical Association guidelines for adolescent preventive services. Arch Pediatr Adolesc Med. 1997;151:958-959.

29. Seppa K, Lepisto J, Sillanaukee P. Five-shot questionnaire on heavy drinking. Alcohol Clin Exp Res. 1998;22:1788-1789.

30. The Alcohol Use Disorders Identification Test: Guidelines for Use in Primary Health Care. Geneva, Switzerland: World Health Organization, 1989.

31. Saunders JB, Aasland OB, Babor TF, et al. Development of the Alcohol Use Disorders Identification Test (AUDIT): WHO collaborative project on early detection of persons with harmful alcohol consumption--Il. Addiction. 1993; 88:791-804.

32. Block G, Gillespie C, Rosenbaum EH, Jenson C. A rapid food screener to assess fat and fruit and vegetable intake. Am J Prev Med. 2000;18:284-288.

33. Gans KM, Sundaram SG, McPhillips JB, Hixson ML, Linman Carlton RA. Rate your plate: an eating pattern assessment and educational tool used at cholesterol screening programs. J Ntr Educ. 1993;25:29-36.

34. Ory MG, Jordan PJ, Bazzare T. The Behavior Change Consortium: setting the stage for a new century of health behavior change research. Health Educ Res. 2002;17:500-511.

35. University of Washington Health Promotion Research Center. Rapid Assessment Physical Activity Scale (RAPA). Available at: http://hmcrc. srph.tau.edu.

36. Society for Research on Nicotine and Tobacco Web site. Available at http://hmcrc.srph.tamu.edu/Measurement\%20folder/Smoking/ Tobacco\%20SNT.pdf.
37. Prochaska JJ, Sallis JF, Long B. A physical activity screening measure for use with adolescents in primary care. Arch Pediatr Adolesc Med. 2001;155:554-559.

38. Centers for Disease Control and Prevention. National Center for Chronic Disease Prevention and Health Promotion. Youth Risk Behavior Surveillance System. Available at: http://www.cdc.gov/Healthy Youth/yrbs/about_yrbss.htm.

39. Choi WS, Gilpin EA, Farkas AJ, Pierce JP. Determining the probability of future smoking among adolescents. Addiction. 2001;2:313-323.

40. North Carolina Department of Health and Human Services. Physical activity and nutrition behaviors monitoring form. Available at: http:// www.eatsmartmovemorenc.com/data/PAN\%20Behaviors\%20Monitori ng\%20Form.pdf

41. Jackson C. Cognitive susceptibility to smoking and initiation of smoking during childhood: a longitudinal study. Prev Med. 1998;27:129-134.

42. Knight JR, Shrier LA, Bravender TD, Farrell M, Vander Bilt J, Shaffer HJ. A new brief screen for adolescent substance abuse. Arch Pediatr Adolesc Med. 1999;153:592-596.

43. Knight JR, Sherritt L, Shrier La, Karris SK, Chang G. Validity of the CRAFFT substance abuse screening test among adolescent clinic patients. Arch Pediatr Adolesc Med. 2002;156:607-614.

44. Cummings LH, Chan KK, Burns KM, Blume AW, Larimer M, Marlatt GA. Validity of the CRAFFT in American-Indian and Alaska-Native adolescents: screening for drug and alcohol risk. J Stud Alcohol. 2003:64:727-732.

45. Prochaska JJ, Sallis JF. Reliability and validity of a fruit and vegetable screening measure for adolescents. J Adolesc Health. 2004;34:163-165.

46. Klesges LM, Baranowski T, Beech B, et al. Social desirability bias in self-reported dietary, physical activity and weight concerns measures in 8- to 10-year old African-American girls: Results from the Girls Health Enrichment Multisite Studies (GEMS). Prev Med. 2004;38: S78-S87.

47. Welk GJ, Corbin CB, Dale D. Measurement issues in the assessment of physical activity in children. Res Q Exerc Sport. 2000;71(2 Suppl): S59-S73.

48. Substance Abuse and Mental Health Services Administration. Results from the 2002 National Household Survey on Drug Use and Health: National Findings. Pediatrics. 2001. Rockville, MD.

49. Prochaska JJ, Sallis JF, Rupp J. Screening measure for assessing dietary fat intake among adolescents. Prev Med. 2001;33:699-706.

50. Dennison BA, Jenkins PL, Rockwell HL. Development and validation of an instrument to assess child dietary fat intake. Prev Med. 2000;31:214-224.

51. Will JC, Farris RP, Sanders CG, Stockmyer CK, Finkelstein EA. Health promotion interventions for disadvantaged women: overview of the WISEWOMAN projects. J Womens Health. 2004;13:484-502.

52. Tunis SR, Stryer DB, Clancey CM. Practical clinical trials. Increasing the value of clinical research for decision making in clinical and health policy. JAMA. 2003;290:1624-1632.

53. Glasgow RE, Magid DJ, Beck A, Ritzwoller D, Estabrooks PA. Practical clinical trials for translating research to practice: design and measurement recommendations. Med Care. In press.

54. Wagner $\mathrm{EH}$. The role of patient care teams in chronic disease management. BMJ. 2000;320:569-572.

55. Babor TF, Sciamanna CN, Pronk N. Assessing multiple risk behaviors in primary care: screening issues and related concepts. Am J Prev Med. $2004 ; 27(25): 42-53$ 